\title{
Imaginando Mundos: \\ Didáctica Proyectual para Aprendizajes Significativos y Colaborativos
}

\author{
Imagining Worlds: Project Didactics for Significant and Collaborative Learning
}

\author{
María Elena Tosello \\ Universidad Nacional del Litoral, Argentina \\ mtosello@fadu.unl.edu.ar \\ María Georgina Bredanini Colombo \\ Universidad Nacional del Litoral, Argentina \\ gbredani@fadu.unl.edu.ar
}

Matías Dalla Costa

Universidad Nacional del Litoral, Argentina

matiasdallacosta@hotmail.com

\begin{abstract}
One of the challenges faced by design disciplines is how to activate the imagination, motivate and engage students and professors in significant and heuristic learning processes, integrating educative and design technologies in relation to a new epistemological, aesthetic and technical paradigm. A didactic proposal, that encourage a ludic and creative experience of collaborative construction of knowledge, is created starting from the task to imagine, design and build worlds. This article describes the basis, objectives, characteristics and results of the experience carried out in the 2013 Digital Graphics Studio, issued for Architecture and Visual Design students in a public Argentinian University.
\end{abstract}

Keywords: Significant learning; Collaborative learning; Blended learning; Project didactics; Educative technologies.

\section{Introducción}

Desde el punto de vista epistemológico, hoy entendemos que es imposible percibir el mundo por fuera de nuestra percepción. Nuestra observación es parte integrante de lo observado, conocemos sólo lo que podemos observar en un contexto, con determinados valores e instrumentos. Vivimos en un mundo coconstruido por el observador. La idea de una realidad única, objetiva e igual para todos, es sustituida por una idea de realidad intersubjetiva, construida a partir de múltiples miradas, valoraciones e interpretaciones en un espacio de consenso. La realidad es una compleja red de procesos que ocurren simultáneamente en diferentes direcciones y niveles de articulación e interacción.

Estas reflexiones situadas en el contexto de la práctica proyectual, implican la necesidad de la organización de estrategias complejas de colaboración interdisciplinaria, que integren miradas y aportes diversos para enfrentar la complejidad que presenta la realidad actual y permitir la construcción de respuestas proyectuales consensuadas, a partir del intercambio de conocimientos y el trabajo colaborativo. Se vuelve evidente que el universo moderno se encuentra en vías de disipación (Barthes citado por Laddaga, 2010:10), o como plantea Bares, "en una cultura postdisciplinaria, el diseño es una construcción colectiva” (Bares, 2010).

El proyecto, considerado solamente desde el punto de vista expresivo, puede entenderse como una instancia de intercambios de sentidos a partir de medios, códigos y técnicas compartidas, entendiendo estos como generadores de miradas y discursos que hacen emerger mundos a través de un proceso en el cual el proyectista es un participante activo que reconoce problemas, se orienta, adjudica sentidos y crea. La actividad proyectual podría entenderse como un método particular de resolución de problemas (Simon, 2006), que implica una actitud heurística frente al mundo.

Desplazándonos al ámbito de la didáctica proyectual, para desarrollar actitudes heurísticas, es indispensable crear experiencias educativas significativas, que incentiven la expansión de la imaginación, la creatividad y la motivación por descubrir (Cortina, 2013). Según Camilloni (2011), los aprendizajes significativos son orientados a fines, autorregulados $y$ colaborativos. Se trata de favorecer y desarrollar competencias para la innovación adoptando una noción más amplia del aprendizaje, de lograr las condiciones necesarias para potenciar competencias fundamentales como la resolución de problemas, la capacidad de reflexión, la creatividad, la adaptabilidad, el pensamiento crítico, la capacidad de aprender a aprender, la asunción de riesgos, la colaboración, el carácter emprendedor y el desarrollo de destrezas interpersonales multidisciplinarias o soft skills (Cobo, 2013:146). 
Jenkins (2008) propone que el aprendizaje de "destrezas sociales y competencias culturales" sea fomentado y ejercitado en los espacios educativos a partir de: juego (experimentar para aprender a resolver problemas); representación; simulación; apropiación; multitarea; inteligencia colectiva; criterio de selección; navegación transmediática; trabajo en red; negociación y compromiso.

"La alfabetización debe representar la adquisición de las competencias intelectuales necesarias para interactuar tanto con la cultura existente como para recrearla de un modo crítico y emancipador $y$, en consecuencia, como un derecho $y$ una necesidad de los ciudadanos de la sociedad informacional." (Freire, 1989)

La pregunta clave que se plantea en este punto es ¿cómo activar la imaginación, motivar y comprometer a los estudiantes y al equipo docente en procesos de aprendizaje heurísticos, significativos y colaborativos? ¿Tienen las TIC algún rol en estos procesos? ¿Cuál?

\section{Propuesta Didáctica}

\section{Objetivos}

El desafío del Taller de Gráfica Digital 2013 (TGD) consistió en formular una propuesta didáctica que promoviera aprendizajes significativos y colaborativos, y motivara a experimentar estrategias novedosas de diseño y representación integrando las potencialidades del medio digital y asumiendo una actitud participativa, exploratoria y lúdica; así como reflexionar sobre la tarea del diseñador, en tanto sujeto potenciador de respuestas innovadoras y creativas en relación a un nuevo paradigma epistemológico, estético y técnico.

\section{Descripción de la experiencia}

Con estos objetivos se diseñó una experiencia cuya consigna fue "imaginar, proyectar y construir mundos a través de diversas representaciones que propongan nuevas espacialidades para el establecimiento, desplazamiento e intercambio". Retomando a Simon (Óp.Cit.), para las ciencias artificiales el mundo no es algo dado, sino una idea, un proyecto. El proyecto consiste en imaginar y construir mundos, innumerables mundos posibles que expresen nuevas y múltiples formas de habitar.

Si bien podrían imaginarse una infinidad de mundos, por cuestiones prácticas la experiencia comenzó con la definición de las características de dos mundos, a partir de los cuales surgieron una multiplicidad de propuestas diversas, una por cada grupo de alumnos. Se caracterizaron colaborativamente los elementos naturales y los aspectos culturales de cada mundo, según 18 categorías previamente elaboradas por la cátedra. El primer mundo debía tener cierta lógica, racionalidad, probabilidad, predictibilidad, etc., mientras que el segundo debía ser ilógico, irracional, improbable, impredecible, etc.

Luego de esta actividad, los alumnos se dividieron en dos comisiones que representaron los mundos según distintas aproximaciones. La comisión A los representó desde la mirada del sujeto, en relación a las características vivenciales y fenomenológicas del espacio social, a través de un video digital colaborativo, un relato espacio-temporal construido a partir de imágenes, videos y sonidos capturados y editados por los alumnos, resignificando su contexto. Estos recursos se subieron al espaciointerfaz del taller http://web.tgdfadu.com.ar/ y conformaron la Base de Datos Colaborativa del TP1A.

La comisión B representó parte o la totalidad de cada mundo desde el punto de vista del objeto, sus características espaciales y expresivas, a través de un objeto tridimensional complejo diseñado y fabricado en función de lógicas de diseño paramétrico. Se diseñaron y editaron secciones apropiables a partir del modelado vectorial-bidimensional. De este proceso, se obtuvo la superficie resultante de la transición de las secciones: un objeto 3D que fue reajustado y construido (Figura 1). Las secciones realizadas por cada grupo también se subieron a la Base de Datos Colaborativa del TP1B para conformar un banco de recursos compartidos

En un segundo momento, ambas comisiones se integraron para diseñar y desarrollar espacios virtuales interactivos de representación simbólica y carácter lúdico-exploratorio, a partir de los conceptos: hipermedio, interfaz y base de datos, fundamentado en la bibliografía y en el análisis de antecedentes. Estos espacios virtuales (Figura 2) debían proponer al usuario ciertas experiencias que le permitieran vivenciar las características del mundo elegido en el TP1, y constituir una interfaz de acceso a una base de datos de elementos multimedia (textos, imágenes, sonidos y videos) originados en los TP1 A y B. Para esto, los alumnos debieron intercambiar el material producido en el TP1.

Los estudiantes podían elegir la comisión (el tipo de objeto a diseñar) y el mundo a representar. El eje conector de los trabajos fue el diseño y la comunicación a través del trabajo y la participación en los espacios físicos y virtuales del taller, entendiendo que la tecnología digital es un medio y no el fin de la actividad proyectual.

Se trabajó con una clase presencial semanal y dos espacios virtuales complementarios. El primero es el espacio de acceso abierto de TGD en el Entorno Virtual UNL (http://entornovirtual.unl.edu.ar/course/view.php?id=627), que funciona sobre Moodle, y contiene el material didáctico: enunciados de trabajos prácticos, clases (publicadas en slideshare), tutoriales de software, cuestionarios, segmentos de películas y sitios web recomendados. Este espacio además, permitió la comunicación pública a través de los foros y privada a través del servicio de mail.

Complementaba el Entorno Virtual UNL, el espacio-interfaz web.tgd (http://web.tgdfadu.com.ar/), desarrollo ad hoc que aloja las siguientes bases de datos: "Constructores de conocimientos" (información sobre docentes y alumnos); las BD Colaborativas del TP1A (imágenes, videos y sonidos), del TP1B (imágenes y archivos de Rhinoceros) y del TP2 (sitios web); el espacio de TGD en Facebook, el canal de Youtube, web de FADU, Google Drive, Dropbox, Prezi, etc. 

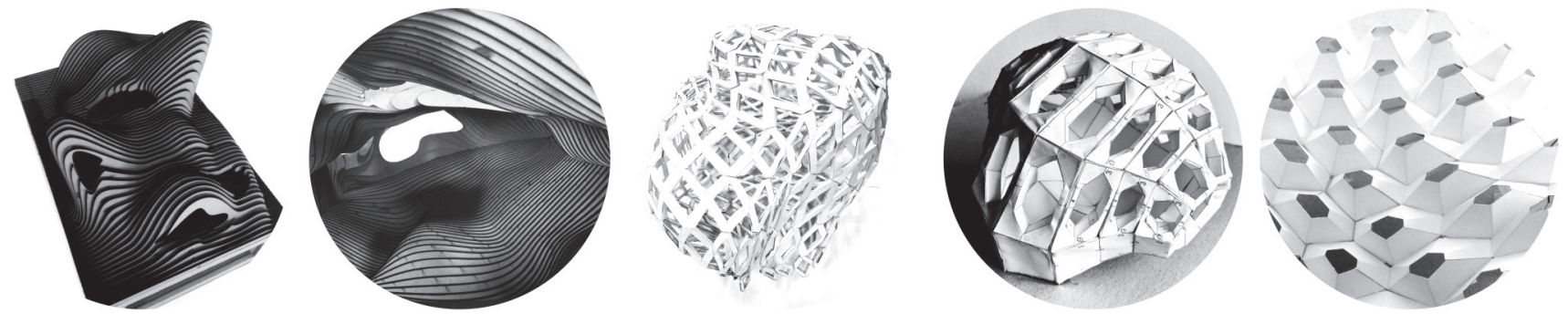

Figura 1: Mundos diseñados por los alumnos aplicando lógicas de diseño paramétrico.

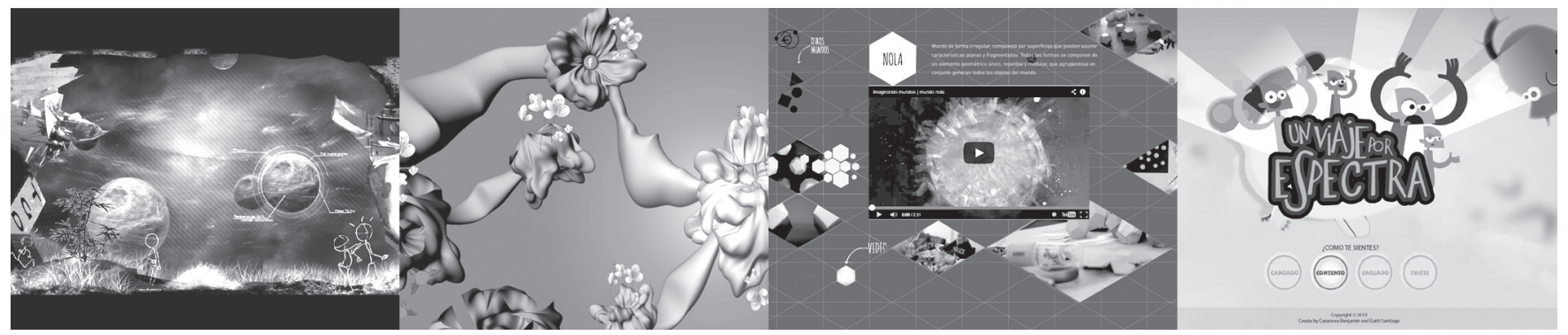

Figura 2: Espacios virtuales interactivos diseñados por los alumnos para vivenciar las características de los mundos.

\section{La Educación Universitaria en un Nuevo Contexto. El Aprendizaje Combinado.}

Se calcula que Internet tiene más de 2.400 millones de usuarios (34\% de la población mundial), un 565\% más que en el año 2000. Somos 1.000 millones de usuarios en Facebook y más de 500 millones en Twitter, todos creando y compartiendo contenidos. Existen aproximadamente 4.000 millones de cuentas de email y más de 650 millones de páginas web activas (Grané Oró, 2013:48).

Como Internet duplica su tamaño cada 2 años, somos cada vez más selectivos y demandamos contenidos útiles, pertinentes, interesantes y capaces de generarnos experiencias significativas. Interactuar con esos contenidos nos motivará, no sólo a aprovecharlos, sino a disfrutarlos y a compartirlos (Cortina, 2013). En este contexto, la educación universitaria debe redefinir su misión y sus métodos; hasta su propio nombre, que hace referencia a la universalidad del saber, pierde sentido en una sociedad en la que el conocimiento y la información crecen tan exponencialmente que resultaría imposible reunir todo el saber conocido. La autoridad académica ya no se basa en la "posesión del saber", hoy el conocimiento es flexible, cambiante y de autoría social, un conocimiento en red, una inteligencia colectiva (Lévy, 2004), y "la nube se convierte en el espacio donde almacenar la información, comunicarse, relacionarse, compartir ideas, trabajar, leer, visualizar, crear contenidos, aprender..." (Bergmann \& Grané Oró, 2013:18).

La universidad debe integrarse a esa red y participar de ese espacio a través de proyectos educativos innovadores que actualicen los procesos de enseñanza-aprendizaje y fomenten la construcción colaborativa de conocimientos y la adquisición de nuevas habilidades, en entornos educativos de acceso abierto. La incorporación a la educación presencial de la potencialidad comunicacional, abierta y transformadora de las TIC, promueve el aprendizaje colaborativo y permite generar un nuevo tipo de racionalidad basada en un conocimiento transversal y múltiple, y la construcción de un pensamiento autónomo y crítico que se apoya en el compromiso y la habilidad del trabajo "entre" (Bessone \& Garramuño, 2004), a partir del diálogo multidireccional entre sujetos, objetos, espacios y medios.

La experiencia en la asignatura optativa Taller de Gráfica Digital durante 2013, entrelaza una propuesta didáctica para promover aprendizajes significativos y colaborativos, y competencias para la innovación, con una metodología de aprendizaje combinado que complementa y potencia los procesos presenciales con recursos y actividades en entornos educativos virtuales (Figura 3), desarrollados con Tecnologías de Aprendizaje Colaborativo (TAC).

Estas metodologías y tecnologías suponen un cambio profundo en los procesos de adquisición de conocimiento. "Un entorno de aprendizaje online es un espacio más allá de la información. Implica una visión de cómo se enseña y de cómo se aprende." (Grané Oró, Óp.Cit.:49) Se diseña siguiendo objetivos específicos; integra contenidos elaborados o seleccionados; incluye experiencias y actividades; permite el seguimiento y la evaluación de los procesos y no sólo de resultados; define diferentes roles para los participantes, etc. Crear un entorno educativo en Internet, implica un proceso con múltiples decisiones interrelacionadas. Desde la concepción hasta la visualización del proyecto, es importante considerar su adecuación para responder a necesidades de aprendizaje, destinatarios y contextos concretos (Grané Oró, Ibid.:50). En nuestro caso, el aprendizaje de contenidos y procedimientos vinculados a la aplicación de instrumentos digitales en el diseño, en un taller proyectual de grado. 


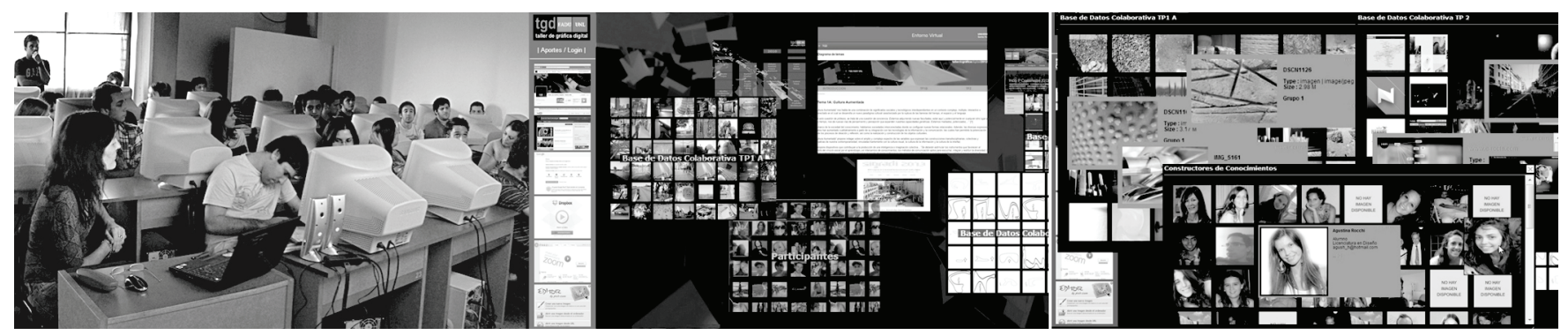

Figura 3: Aprendizaje Combinado: el ámbito simbiótico de interacción docente-alumno de TGD.

La metodología general se organiza en dos etapas: Etapa de Planificación, Análisis, Diseño y Desarrollo; y Etapa de Experimentación, Evaluación y Ajustes. Es fundamental realizar una detallada planificación de las estrategias de acción didáctica (diseño formativo), y de diseño y desarrollo de los espaciosinterfaz que integran el ámbito simbiótico de interacción docentealumno (diseño comunicacional e interactivo), el cual involucra decisiones tecnológicas. Se parte de la adecuación didáctica (necesidades, destinatarios, contexto), hacia el diseño de la comunicación y la interactividad, desde la flexibilización tecnológica (Grané Oró, Ibid.:57). Todas estas variables son interdependientes.

1- En la Etapa de Planificación se abordan los siguientes aspectos interrelacionados: El Análisis del perfil de los usuarios (necesidades, intereses, hábitos); y el Diseño de las estrategias de acción: definición de contenidos, diseño y desarrollo de recursos didácticos (clases, cuestionarios, búsqueda de tutoriales, etc.), actividades prácticas e instrumentos de evaluación. Luego se aborda el Diseño de interfaces (gráfica y de navegación) -etapa de particular importancia en entornos educativos destinados a disciplinas proyectuales, ya que el diseño influye en el grado de comprensión de los conocimientos-, en relación al Desarrollo Tecnológico, en el cual es imprescindible analizar las capacidades técnicas del contexto, investigar y adaptar las tecnologías disponibles en función a las estrategias didácticas y actividades diseñadas, e integrarlas con desarrollos originales para la gestión y el acceso al conocimiento.

2- Etapa de Experimentación: realización y testeo de la experiencia; análisis de fortalezas y debilidades; ajuste de la propuesta y ejecución de nuevas experiencias.

Según Simon (Óp.Cit.), una metodología válida para el desarrollo de sistemas de interacción, es construirlos y observar su comportamiento. El trabajo teórico debe acompañarse de una considerable dosis de trabajo experimental. Puede darse toda una serie de ciclos de generación y prueba.

\section{Evaluación de la Experiencia}

La experiencia desplegó acciones colaborativas entre profesores y estudiantes dedicados al diseño descentralizado de discursos, objetos y espacios; y el diseño de dispositivos que facilitaron la comunicación de las colaboraciones y el debate, y que se concibieron como el hábitat propio de estas prácticas.

Al finalizar el cursado se realizó una encuesta de participación voluntaria y anónima, con 30 preguntas clasificadas en 3 categorías: Perfil, Propuesta Didáctica, Espacio-Interfaz, y fue respondida por: 93\% de estudiantes, 2 docentes y 1 ayudantealumno.

Los estudiantes tienen entre 20 y 30 años; el $61 \%$ hace más de 10 años que usa Internet y el 39\% restante hace entre 5 y 10 años. El $96 \%$ se conecta a Internet "varias veces por día" y el $82 \%$ pasa allí entre 3 y 6 horas diarias. El 100\% desarrolla en Internet actividades académicas, el $96 \%$ realiza actividades sociales, el $82 \%$ actividades comunicacionales y el $75 \%$ actividades recreativas. Los sitios que visitan regularmente son: $88 \%$ redes sociales, $84 \%$ buscadores, $81 \%$ correo electrónico, $58 \%$ sitios de video.

El 93\% piensa que contar con un espacio virtual además de las clases presenciales, contribuye a mejorar el proceso de aprendizaje.

“...ayuda porque mantiene el contacto constante con profesores y alumnos, lo que permite que el diálogo se extienda más allá de los horarios de cursado y posibilita las consultas inmediatas y el avance de los trabajos prácticos sin tener que esperar a la próxima clase. Además, la consulta que hace un compañero le puede servir al resto."

El $88 \%$ piensa que fue positivo haber anexado la web.tgd al entorno virtual de la UNL; el 79\% utilizó estos sitios para revisar enunciados de los TP, bibliografía, clases y tutoriales; el 67\% para compartir información, recursos y contenidos; y el 63\% para realizar consultas y participar en foros. El $93 \%$ opinó que los foros son un instrumento útil.

El $82 \%$ opinó que le gustaría contar con un espacio personal en Internet que reúna todos los sitios y recursos que utiliza regularmente; y el $83 \%$ piensa que los espacios virtuales interactivos son parte de su hábitat. Algunos comentarios referidos a estos espacios:

"Los espacios interactivos constituyen una parte significativa de nuestro habitar cotidiano..." "Son un nuevo espacio del 
conocimiento y las relaciones sociales... Nacimos y vivimos en un mundo de interactividad y tecnología, y es importante reflexionar acerca de los cambios que hacen a la evolución de la sociedad en la cual estamos inmersos".

\section{Reflexiones Finales}

Desde el principio de la experiencia se trabajó especialmente en crear un clima de confianza para favorecer la participación de los alumnos. En las clases presenciales se recuperaban los aportes realizados en foros y cuestionarios, y finalizando el cuatrimestre, los alumnos compartían sus conocimientos entre ellos. Las experiencias realizadas demostraron que desarrollar las actividades educativas en un ámbito de interacción simbiótico es muy motivante para los alumnos, una motivación que nace del interés genuino por aprender, que no espera ninguna compensación externa al propio aprendizaje (Grané Oró, Óp.Cit.:55)

La educación "face-to-face" permite al profesor desplegar una serie muy variada de artilugios comunicacionales: hacer silencios, bromas, dar énfasis al discurso levantando o bajando la voz; y a algunos alumnos, expresar sus ideas en forma coloquial. Pero en otros casos, los foros les permitieron decir cosas que oralmente no se habrían animado a expresar.

La principal innovación de esta propuesta se fundó en la interdependencia y vivencia simultánea o alternativa de los espacios físicos y virtuales del taller, que posibilitó una estimulante y dinámica construcción colaborativa del conocimiento y permitió a los alumnos desplazarse hacia el nuevo paradigma y desarrollar una mirada polifónica de la realidad.

¿Es necesario seguir creando contenidos que ya existen en la web? ¿No es más adecuado contar con profesores capaces de seleccionar materiales de calidad existentes en repositorios educativos de acceso abierto? Es tiempo de construir entornos virtuales de aprendizaje basados en competencias más que en contenidos, espacios para la resolución de problemas en forma colaborativa, abiertos a los aportes de todos; y de diseñar propuestas didácticas que busquen maneras creativas de motivar el aprendizaje, que se interroguen sobre qué contenidos y procedimientos enseñamos, pero fundamentalmente sobre cómo los enseñamos, orientándose al aprendizaje contextual (situated learning), pensando en los estudiantes, organizando proyectos y actividades conectados con sus intereses (Grané Oró, Ibíd.).

Somos protagonistas de una nueva etapa en la educación universitaria, marcada por el cambio en la apropiación del espacio, el avance constante de la tecnología y la necesidad de flexibilidad, adaptación y desarrollo de nuevos hábitos y destrezas para mantener siempre abiertas las preguntas que provienen de la experiencia y conocimiento de un mundo en constante movimiento, a las cuales la educación debe responder con imaginación.

\section{Agradecimientos}

Este trabajo es parte del proyecto de investigación CAI+D’09 №12/A003 “El aprendizaje combinado o blended-learning en la universidad pública. Estrategias para su aplicación en un taller proyectual de grado" de la Facultad de Arquitectura, Diseño y Urbanismo, de la Universidad Nacional del Litoral. Agradecemos los generosos aportes de: Cecilia Zorzón, Cecilia Scándolo, Álvaro Dorigo, Guillermo Mántaras, Cristian Dovis y Nicolás Gualtieri.

\section{Referencias}

Bares, N. (2010). Conferencia Inaugural Maestría en Arquitectura. FADU UNL.

Bessone, M., Garramuño, S. (2004). Un Nuevo Tipo de Racionalidad Construida a partir de la Relación entre Sujetos, Objetos y Multimedios. En 2do Congreso Internacional de Educación UNL. Santa Fe, Argentina.

Camilloni, A. (2011). Curso La extensión en la formación universitaria, educación experiencial, UNL. Santa Fe, Argentina.

Cobo, C. (2013) ¿De qué hablamos cuando nos referimos a «competencias para la innovación»?. En La universidad en la nube. Recuperado de http://www.Imi.ub.edu/transmedia21/vol6/La_Universidad_en_la_N ube.pdf

Cortina, S. (2013). La nueva evolución de la información. Recuperado de http://foroalfa.org/articulos/la-nueva-evolucion-de-la-informacion

Freire, P. (1989). Alfabetización. Lectura de la palabra y lectura de la realidad. Madrid: Paidós-MEC.

Grané Oró, M. (2013) Relaciones de diseño en entornos de formación online, en La universidad en la nube. Recuperado de: http://www.Imi.ub.edu/transmedia21/vol6/La_Universidad_en_la_N ube.pdf

Jenkins, H. (2008) Convergence Culture, Editorial Paidós.

Laddaga, R. (2010) Estética de la emergencia, Adriana Hidalgo Editora. Buenos Aires.

Lévy, P. (2004) Inteligencia colectiva. Washington DC. Recuperado de: http://inteligenciacolectiva.bvsalud.org

Simon, H. (2006) Las ciencias de lo artificial, Editorial Comares. 